\title{
Lung Sound Analysis Provides A Useful Index For Both Airway Narrowing And Airway Inflammation In Patients With Bronchial Asthma
}

This article was published in the following Dove Press journal:

Journal of Asthma and Allergy

\author{
Terufumi Shimoda $\mathbb{D}^{1,2}$ \\ Yasushi Obase ${ }^{3}$ \\ Yukio Nagasaka ${ }^{4}$ \\ Reiko Kishikawa (D) ${ }^{2}$ \\ Sadahiro Asai ${ }^{1}$ \\ 'Department of Allergy, San Remo \\ Rehabilitation Hospital, Sasebo, Japan; \\ ${ }^{2}$ Department of Allergy, Clinical Research \\ Center, Fukuoka National Hospital, \\ Fukuoka, Japan; ${ }^{3}$ Department of \\ Respiratory Medicine, Nagasaki \\ University Graduate School of \\ Biomedical Sciences, Nagasaki, Japan; \\ ${ }^{4}$ Department of Respiratory Medicine, \\ Kyoto Respiratory Center, Otowa \\ Hospital, Kyoto, Japan
}

\begin{abstract}
Background: The expiration-to-inspiration sound power ratio in a midfrequency range (E/I MF), a parameter of lung sound analysis (LSA), has been reported to be useful as an index of airway inflammation in patients with bronchial asthma. However, the E/I MF reflects airway narrowing caused by airway inflammation, and there is thus concern that it may not be an index of airway eosinophilic inflammation itself.
\end{abstract}

Methods: A total of 131 patients with bronchial asthma were classified into four groups according to the presence or absence of airway narrowing and airway inflammation to examine whether the E/I MF could serve as an index of airway inflammation.

Results: The E/I MF was significantly higher in patients with a normal forced expiratory volume in one second $\left(\mathrm{FEV}_{1}\right)$ and high fractional exhaled nitric oxide (FeNO), those with a low $\mathrm{FEV}_{1}$ and normal FeNO, and those with a low $\mathrm{FEV}_{1}$ and high FeNO than in those with a normal $\mathrm{FEV}_{1}$ and normal FeNO $(\mathrm{p}<0.05-0.01)$. In particular, the E/I MF was high even in the patients who had no airway narrowing but had airway inflammation $(p<0.01)$. The results of multivariate analysis of factors involved in FeNO in patients with a normal $\mathrm{FEV}_{1}$ revealed that the $\mathrm{E} / \mathrm{I} \mathrm{MF}$ was an independent factor $(\mathrm{p}=0.0281)$.

Conclusion: The E/I MF is a useful index of airway inflammation in the treatment of asthma, regardless of the presence or absence of airway narrowing.

Keywords: airway inflammation, bronchial asthma, E/I MF, FeNO, lung sound analysis

\section{Introduction}

Two phenotypes, Th2-high and Th2-low, have been identified in cases of airway inflammation associated with bronchial asthma. The Th2-high phenotype consists of eosinophilic inflammation responsive to inhaled corticosteroid (ICS) treatment, whereas the Th2-low phenotype consists of neutrophilic inflammation resistant to ICS treatment. Duration of these types of airway inflammation brings about airway hyperreactivity and airway narrowing, leading to the airway remodeling that makes the asthma more severe and intractable. ${ }^{1-3}$ In patients with bronchial asthma, the frequency and intensity of auscultatory sounds vary according to variations in the respiratory flow, airway narrowing due to airway injury, and secretions attached to the airway. ${ }^{4}$

We have previously reported that the expiration-to-inspiration sound power ratio in a midfrequency range (E/I MF), a parameter of lung sound analysis (LSA), is a useful index of airway narrowing and airway inflammation in asthma without treatment. $^{5-8}$ We have also reported that the E/I MF increases not only in cases
Department of Allergy, San Remo

Rehabilitation Hospital, 14848-I Egamicho,

Sasebo 859-3244, Japan

Tel $+81-956-58-5900$

Fax +8I-956-58-5550

Email shimoda2642@e-broad.ne.jp 
of eosinophilic inflammation in bronchial asthma but also in cases of neutrophilic inflammation and mixed-type inflammation with them. ${ }^{7,8}$ However, the E/I MF correlates with the forced expiratory volume in one second $\left(\mathrm{FEV}_{1}\right)$, which is an index of airway narrowing, as well as with the sputum eosinophil count and fractional exhaled nitric oxide (FeNO), which are known as indices of airway eosinophilic inflammation. Therefore, there is a concern that the E/I MF is an index of airway narrowing resulting from airway inflammation but may not be an index of airway inflammation itself especially in the patients with airway inflammation amended by ICS treatment.

In this study, patients with bronchial asthma who were receiving ICS treatment were divided into four groups by combination of $\mathrm{FEV}_{1}$ and FeNO to examine whether the E/I MF could be an index of airway inflammation in bronchial asthma.

\section{Methods}

\section{Subjects And Study Design}

A total of 131 outpatients diagnosed with bronchial asthma from September 2012 to August 2015, who were free of other respiratory disease complications than asthma, such as chronic obstructive pulmonary disease (COPD) or cardiac disease, were subjected. Patients with acute respiratory infection within seven days were excluded. No patients had asthmatic exacerbation, and all patients were undergoing ICS treatment and were nonsmokers or former smokers with less than 10 pack/years. All patients fulfilled the criteria of the Global Initiative for Asthma Guidelines ${ }^{9}$ and reported a history of asthmatic symptoms, including recurrent cough, wheezing or dyspnea, and had positive airway hyperresponsiveness and airway reversibility.

LSA, blood examinations, spirometry, FeNO measurements, and sputum induction and processing were performed in accordance with previously reported procedures. ${ }^{5,8,10-12}$ Anti-asthma drugs were discontinued for at least $24 \mathrm{~h}$ prior to examination.

The correlation of the E/I MF with respiratory function, FeNO, or the sputum eosinophil percentage was examined. Regarding airway narrowing, normal $(\mathrm{N})$ was defined when $\mathrm{FEV}_{1} / \mathrm{FVC} \geq 70 \%$ and $\mathrm{FEV}_{1}, \%$ pred $\geq 80 \%$, otherwise the patient was classified as abnormal airway function (A). Regarding airway eosinophilic inflammation, abnormal FeNO was defined as FeNO $\geq 38 \mathrm{ppb}$, and normal FeNO was defined as FeNO $<38 \mathrm{ppb}$. ${ }^{13}$ According to the combinations of normal (N) or abnormal (A) FEV1 and FeNO, the patients were divided into four groups; FEV1 (N)-FeNO (N) accounted for 54\% (group NN); FEV1 (N)-FeNO (A), 22\% (group NA); FEV1 (A)-FeNO (N), 16\% (group AN); and FEV1 (A)-FeNO (A), 8\% (group AA), and patient characteristics and $\mathrm{E} / \mathrm{I} \mathrm{MF}$ values were compared among these groups.

The study protocol was approved by the ethics committee of Fukuoka National Hospital (protocol no.: 23-14); all participants received verbal and written information about the study before providing their informed consent. The patient consent was written informed consent, and that this study was conducted in accordance with the Declaration of Helsinki.

\section{Measurement Of The FeNO Concentration, Pulmonary Function, Hypersensitivity And Airway Reversibility} Following the guidelines published by the American Thoracic Society (ATS), FeNO was measured using the online singlebreath method and a fast-response $(0.02 \mathrm{~s})$ chemiluminescence analyzer (Sievers Nitric Oxide Analyzer NOA 280i, GE Analytical Instruments, Boulder, CO, USA). ${ }^{11,14}$ All measurements were obtained using a mouth pressure of $16 \mathrm{cmH}_{2} \mathrm{O}$, corresponding to an expiratory flow of $50 \mathrm{~mL} / \mathrm{s}$. The FeNO concentrations were recorded as the average of 3 values.

Bronchial hypersensitivity was detected by provocative concentration of acetylcholine (Ach) causing a $20 \%$ decrease in $\mathrm{FEV}_{1}\left(\mathrm{PC}_{20}\right)<8000 \mathrm{mcg} / \mathrm{mL}$ and airway reversibility was detected by $\mathrm{FEV}_{1} \geq 12 \%$ and increased by $200 \mathrm{~mL}$ after inhalation of a bronchodilator. Bronchial hypersensitivity test and airway reversibility test were performed in all patients at any point during the clinical course.

\section{LSA}

LSA was performed according to a previously described procedure. ${ }^{5,8}$ The sound recording was performed in a quiet room, but not in a soundproof booth, in the outpatient department. During the patients breathed deeply during the breath sound recording, lung sounds were recorded using a hand-held microphone for $\geq 30$ seconds over the left lung base. The recording system consisted of an electrostethoscope containing a wide-range audio sensor attached to the inside of a diaphragm (Bio-Sound Sensor BSS-01; Kenz Medico, Saitama, Japan), a signal processing system, and a personal computer. The sensor had a bandpass filter range of $40-2500 \mathrm{~Hz}$ and a reliable sound-collecting ability in the $40-2000 \mathrm{~Hz}$ range. The 
recorded sounds were analyzed by fast Fourier transform using a sound spectrometer software (Easy-LSA; Fukuoka, Japan) and were displayed as a spectrograph.

We defined a frequency range of 200 to $400 \mathrm{~Hz}$ as the midfrequency range and determined the inspiration sound power, expiration sound power, and the $\mathrm{E} / \mathrm{I}$ in this range according to our previous reports. ${ }^{5-8}$

\section{Statistical Analysis}

The characteristics of patients in groups NN, NA, AN and AA were compared by the Wilcoxon/Kruskal-Wallis test, and comparisons by the groups were subsequently performed using the Steel-Dwass method for variables that showed significant differences. The results are shown as medians $(25 \%, 75 \%)$. Among the patient characteristics, nominal variables (sex, severity, history of childhood asthma, atopic/nonatopic, ICS amount, concomitant medication with ICS) were compared by Pearson's chi-square test. The correlation of the E/I MF with respiratory function, FeNO, or the sputum eosinophil percentage was determined using Spearman's rank correlation coefficient. A stepwise procedure for multiple regression analysis was used for multivariate analysis of factors involved in FeNO in the normal FEV1 groups (groups NN and NA). The forward selection method was used for selection from among the following variables: sex, age, body mass index (BMI), amount of smoking, log IgE, and E/I MF. Differences were considered statistically significant at $\mathrm{p}<0.05$. JMP 9 (SAS Institute, Inc., Cary, North Carolina, USA) was used for statistical analysis.

\section{Results}

\section{Patient Characteristics And E/I MF Values Of Four Groups Classified By FEVI And FeNO}

A total of 131 patients who had no adventitious lung sounds on auscultation during quiet breathing were classified into four groups (Table 1). Patients in group NN had neither airway narrowing nor airway inflammation, and

Table I Patient Characteristics And E/I MF Value When Classified Into 4 Groups By Combination Of FEVI And FeNO

\begin{tabular}{|c|c|c|c|c|c|}
\hline & NN $(n=7 I)$ & NA $(n=29)$ & AN $(n=21)$ & AA $(n=10)$ & \\
\hline $\begin{array}{l}\text { FEVI } \\
\text { FeNO }\end{array}$ & $\begin{array}{l}\mathbf{N} \\
\mathbf{N}\end{array}$ & $\begin{array}{l}\mathbf{N} \\
\mathbf{A}\end{array}$ & $\begin{array}{l}\mathbf{A} \\
\mathbf{N}\end{array}$ & $\begin{array}{l}\text { A } \\
\text { A }\end{array}$ & $\begin{array}{l}\text { P-value } \\
\text { (Pearson) }\end{array}$ \\
\hline Male/female, $n$ & $18 / 53$ & $14 / 15$ & $4 / 17$ & $4 / 6$ & 0.074 \\
\hline Age, years & $42(34,53)$ & $35(27.5,60)$ & $53(33.5,64.5)$ & $59(47.5,67.5)^{*}$ & \\
\hline $\mathrm{BMI}, \mathrm{kg} / \mathrm{m}^{2}$ & $22.6(20.3,25.5)$ & $23.3(20.1,24.6)$ & $20.5(19.1,21.9) *(\# 0.06)$ & $20.5(18.7,21.9)$ & \\
\hline Severity; step $(1,2,3,4)$ & $25 / 38 / 8 / 0$ & $|2 /| 2 / 4 / \mid$ & $3 / 10 / 3 / 5$ & $0 / 6 / 3 / 1$ & 0.0012 \\
\hline Asthma duration, years & $2(0.7,6)$ & $7(1,17)$ & $8(1,21.5)^{*}$ & $13.5(3.3,18.5)(* 0.07)$ & \\
\hline $\begin{array}{l}\text { History of childhood asthma } \\
\text { (no/yes), n }\end{array}$ & $62 / 9$ & $17 / 12$ & $17 / 4$ & $10 / 0$ & 0.0039 \\
\hline Atopic/non-atopic & $37 / 34$ & $24 / 5$ & $15 / 6$ & $4 / 6$ & 0.0178 \\
\hline Amount of ICS (low/middle/high) & $3 / 67 / 1$ & $5 / 22 / 2$ & $3 / 13 / 5$ & $0 / 9 / 1$ & 0.0025 \\
\hline $\begin{array}{l}\text { Concomitant medicine with ICS } \\
\text { (none/montelukast/salmeterol/ } \\
\text { combination/others) }\end{array}$ & $26 / 7 / 7 / 31 / 0$ & $18 / 1 / 3 / 7 / 0$ & $9 / 0 / 3 / 6 / 3$ & $4 / 1 / 3 / 1 / 1$ & 0.0075 \\
\hline $\lg E(I U / m L)$ & $89(42,25 \mathrm{I})$ & $362(135,1283)^{* * \$}$ & $157(47,244)$ & $187(87,436)$ & \\
\hline $\mathrm{PC} 20(\mu \mathrm{g} / \mathrm{mL})$ & $4177(1250,740 I)$ & $926(325,2057)^{* * * *}$ & $754(356,2146)^{* *}$ & $625(4 \mid 4,1472)^{*}$ & \\
\hline Blood eosinophils, \% & $5.1(2.7,6.8)$ & $9.3(6.4,14.6)^{* * *}$ & $4.4(2.3,8.4)$ & $8.3(6.0,11.3)^{*}$ & \\
\hline Sputum eosinophils, \% & $\mathrm{I}(0,2)$ & $3.5(1.5,6)^{* * * *}$ & $5(1.5,16.5)^{* * *}$ & $10.3(4,27.1)^{* * *}$ & \\
\hline FEVI/FVC, \% & $79.9(76.9,85.2)$ & $77.9(75.8,83.9)$ & $66.8(60.5,69.2)$ & $66.3(63.0,67.8)$ & \\
\hline FEVI,\%pred, \% & $100.9(94.5,108.2)$ & $98.7(93.5,107.5)$ & $79.1(71.4,87.6)$ & $88.4(76.0,103.5)(* 0.08)$ & \\
\hline V50,\%pred, \% & $79.9(64.7,97.5)$ & $66.2(59.8,80.4)$ & $37.6(30.7,48.6)$ & $41.6(36.2,46.2)$ & \\
\hline V25,\%pred, \% & $57.5(45.6,76.6)$ & $54.3(45.0,67.2)$ & $28.8(20.7,33.3)$ & $31.5(28.2,40.6)$ & \\
\hline $\mathrm{E} / \mathrm{MF}$ & $0.30(0.24,0.4 I)$ & $0.43(0.29,0.61)^{*}$ & $0.52(0.34,0.59) * *$ & $0.60(0.4 \mathrm{I}, 0.73) * *$ & \\
\hline FeNO, ppb & $20.5(16.4,24.1)$ & 6I.I $(46.4,86.4)$ & $23.9(19.7,28.2)$ & $79.7(45.5,87.2)$ & \\
\hline
\end{tabular}

Notes: Vs. NN ***p<0.00I, **P<0.0I, *p<0.05; Vs. NA \#: P<0.05; Vs. AN \$: P<0.05. The data are indicated by median (25\%, 75\%). FEVI: A (abnormal); FEVI/FVC <70\% or

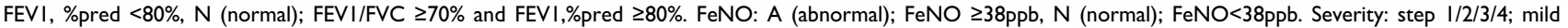
intermittent/mild persistent/moderate persistent/severe persistent. Amount of ICS (low/middle/high); low; conversion to beclomethasone dipropionate (BDP) $\leq 400 \mu$ g/day, middle; 400-800 $\mu \mathrm{g} /$ day; high; BDP: 800-1600 $\mu$ g/day, combination; budesonide/formeterol or salmeterol/fluticasone. 
their asthma was in good control. In group NA, the patients' serum IgE levels were high, the atopic type was common, and the blood and sputum eosinophil percentages were high. In group AN, patients with a long disease duration was predominant, and the sputum eosinophil percentage was surprisingly high. In group AA, the patient age was relatively high, and the blood and sputum eosinophil percentages were high. Airway hyperreactivity was significantly increased in groups NA, AN, and AA compared with group NN. A moderate ICS dose without concomitant medication was predominant in group NA, whereas a high ICS dose was predominant in group AN.

Figure 1 shows the E/I MF values obtained in the four groups of patients classified according to combinations of FEV and FeNO in an easy-to-understand format; these values are excerpted from Table 1. The E/I MF values in groups NA, $\mathrm{AN}$, and AA were significantly higher than those in group $\mathrm{NN}$ (group $\mathrm{NN}=0.30[0.24,0.41]$ versus group $\mathrm{NA}=0.43$ $[0.29,0.61], \mathrm{p}<0.05$; group $\mathrm{AN}=0.52[0.34,0.59], \mathrm{p}<0.01$; and group $\mathrm{AA}=0.60[0.41,0.73], \mathrm{p}<0.01)$.

\section{Correlation Of The E/I MF With Respiratory Function, FeNO, Or Sputum Eosinophil Percentage}

The E/I MF was found to have a significant negative correlation with $\mathrm{FEV}_{1} / \mathrm{FVC}, \mathrm{FEV}_{1}$,\%pred, maximal expiratory flow at $50 \%\left(\mathrm{~V}_{50}\right), \%$ pred, and maximal expiratory flow

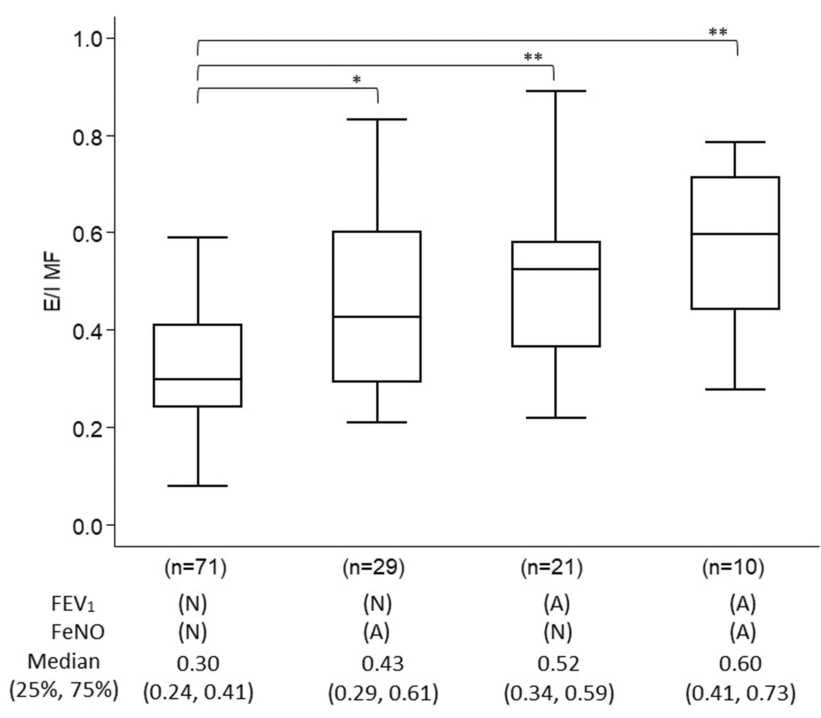

Figure I Comparison of E/I MF values in four groups classified by combinations of FEVI and FeNO. FEVI; abnormal (A) cases were defined as FEVI/FVC $<70 \%$ or FEVI, \%predicted $<80 \%$. Normal $(\mathrm{N})$ cases were defined as FEVI/FVC $\geq 70 \%$ and FEVI, \%predicted $\geq 80 \%$. FeNO; abnormal (A) cases were defined as FeNO $\geq 38 \mathrm{ppb}$, whereas normal $(\mathrm{N})$ cases were defined as $\mathrm{FeNO}<38 \mathrm{ppb}$. ${ }^{*} \mathrm{p}<0.05$, ${ }^{* *} \mathrm{p}<0$. 01 . at $25 \%\left(\mathrm{~V}_{25}\right), \%$ pred, which are indices of airway narrowing ( $\mathrm{r}=-0.199$ to $-0.435, \mathrm{p}=0.0229$ to $\mathrm{p}<0.0001)$. In addition, the E/I MF showed a significant positive correlation with FeNO, which is an index of airway inflammation, and with the sputum eosinophil percentage $(r=-0.264$, $\mathrm{p}=0.0024 ; \mathrm{r}=0.382, \mathrm{p}<0.0001$, respectively; Table 2).

\section{Factors Involved In FeNO In Normal FEVI Groups}

When factors involved in FeNO were examined by multivariate analysis in normal FEV1 groups (groups $\mathrm{NN}$ and NA), sex (male; $\mathrm{t}$-value $=-3.83, \mathrm{p}=0.0002$ ), amount of ex-smoking (t-value $=-2.82, \mathrm{p}=0.0058), \log \operatorname{IgE}$ $(\mathrm{t}$-value $=3.50, \mathrm{p}=0.0007)$, and $\mathrm{E} / \mathrm{I} \mathrm{MF}$ (t-value $=2.23$, $\mathrm{p}=0.0281$ ) were found to be significantly involved (Table 3 ).

\section{Discussion}

In this study, which included patients with bronchial asthma receiving ICS treatment, the E/I MF values were compared among four groups of patients classified according to combinations of $\mathrm{FEV}_{1} / \mathrm{FVC}, \mathrm{FEV}_{1}, \%$ pred, and $\mathrm{FeNO}$. The results revealed $\mathrm{E} / \mathrm{I} \mathrm{MF}$ values to be significantly higher in patients in whom either the FEV1 or FeNO was abnormal, i.e., those with a normal FEV1 and high FeNO (group NA) and those with a low FEV1 and normal FeNO (group AN), and in patients in whom both the FEV1 and FeNO were abnormal (group AA), than in patients with a normal FEV1 and normal FeNO (group NN).

In particular, the $\mathrm{E} / \mathrm{I} \mathrm{MF}$ was found to be an independent factor by multivariate analysis of factors involved in FeNO in patients with bronchial asthma with $\mathrm{FEV}_{1} / \mathrm{FVC} \geq 70 \%$ and $\mathrm{FEV}_{1}, \%$ pred $\geq 80 \%$ who were receiving ICS treatment (groups $\mathrm{NN}$ and NA). Therefore, it is speculated that the E/I MF, in addition to FeNO, is a useful index of the ICS-mediated inhibition of airway inflammation in the treatment of bronchial asthma.

Table 2 Correlation Between E/I MF And Respiratory Function, FeNO, Sputum Eosinophils

\begin{tabular}{|l|l|l|}
\hline vs. Variable & $\begin{array}{l}\text { Spearman Rank } \\
\text { Correlation } \\
\text { Coefficient }(\boldsymbol{\rho})\end{array}$ & $\begin{array}{l}\text { p-Value } \\
\text { (Prob }>|\rho|)\end{array}$ \\
\hline FEV $_{1} / \mathrm{FVC}(\%)$ & -0.369 & $<0.000 \mathrm{I}$ \\
$\mathrm{FEV}_{1}, \%$ pred. (\%) & -0.199 & 0.0229 \\
$\mathrm{~V}_{50} \%$ pred. (\%) & -0.435 & $<0.000 \mathrm{I}$ \\
$\mathrm{V}_{25}, \%$ pred. (\%) & -0.370 & $<0.000 \mathrm{I}$ \\
FeNO (ppb) & 0.264 & 0.0024 \\
Sputum eosinophils (\%) & 0.382 & $<0.000 \mathrm{I}$ \\
\hline
\end{tabular}


Table 3 Factors Involved In FeNO In FEVI Normal Groups (group NN And NA) By Multivariate Analysis

\begin{tabular}{|l|l|l|l|l|l|}
\hline & Estimate & SE & t-Value & p-Value & $\mathbf{( 9 5 \% ~ C l )}$ \\
\hline Sex[F] & -10.04 & 2.62 & -3.83 & 0.0002 & $(-15.254,-4.830)$ \\
Age (years) & 0.21 & 0.16 & 1.28 & 0.2020 & $(-0.115,0.534)$ \\
Ex-smoking (pack-years) & -3.76 & 1.33 & -2.82 & 0.0058 & $(-6.412,-1.116)$ \\
log IgE & 12.16 & 3.47 & 3.50 & 0.0007 & $(5.267,19.060)$ \\
E/I MF & 26.82 & 12.02 & 2.23 & 0.0281 & $(2.945,50.685)$ \\
\hline
\end{tabular}

Notes: $\mathrm{R}^{2}=0.336$, analysis of variance $<0.001$.

In asthmatic patients, it is believed that FeNO allows assessment of eosinophilic inflammation of the airway. ${ }^{15,16}$ In group NA, the serum IgE level was high, showing increased airway hyperreactivity. In group $\mathrm{AN}$, which included many patients with a history of childhood asthma, increased airway hyperreactivity was found in two forms. In one form, FeNO was normal, but the sputum eosinophil percentage was relatively high, showing the persistence of eosinophilic inflammation. In the other form, noneosinophilic airway inflammation is present, showing the probable involvement of neutrophilic airway inflammation. In group AA, patients of an advanced age were predominant, and airway hyperreactivity was increased. There were significant differences in the ICS amount and types of concomitant medication with ICS among the four groups of patients. Differences in the treatment regimens may have had an influence on airway narrowing and airway inflammation, causing some effects on the E/I MF values. Therefore, it seems possible that the treatment regimen can be altered with reference to the E/I MF, as well as FeNO.

In this study, multivariate analysis showed that male patients tended to be predominant among those who had abnormal FeNO. However, the reason for the predominance of male patients remains unclear. In regard to the influences of sex on asthma control or severity of the disease, some studies have shown that severe cases are more frequent among female patients; ${ }^{17,18}$ in contrast, there have also been reports indicating that respiratory failure is more likely to occur in $\operatorname{men}^{19}$ and describing little difference in respiratory failure according to sex, ${ }^{20,21}$ making this issue controversial.

In patients with asthma, respiratory function has been used as an index of airway narrowing and FeNO has been used as an index of airway eosinophilic inflammation. The present study suggests that the E/I MF obtained by LSA is useful as an index of both airway narrowing and airway inflammation. A number of previous studies of lung sounds in asthmatic patients have analyzed abnormal sounds and rales obtained on routine auscultation and analyzed lung sounds during airway narrowing, ${ }^{22-24}$ but few studies have focused on correlations between the results of LSA and indicators of airway inflammation. In this study, we found that the remaining minimal airway inflammation was detectable by LSA in asthmatic patients who showed normal findings on usual auscultation, normal respiratory function. The $\mathrm{E} / \mathrm{I} \mathrm{MF}$ is a turbulent flow sound energy ratio that includes respiratory cycle elements of air transfer in the airway and serves as an index of obstructive airway narrowing. Therefore, the E/I MF characteristically has good sensitivity, which allows the detection of mild airway narrowing due to slight edema of the bronchial mucosa resulting from airway inflammation in patients with asthma at early onset that is not associated with airway remodeling. Slight airway narrowing cannot be detected by the usual respiratory function test, whereas the E/I MF is capable of detecting them. The main cause of airway narrowing in cases of mild asthma is eosinophilic airway inflammation. However, FeNO does not have sufficient power to detect the severity of eosinophilic airway inflammation in patients with mild asthma. Therefore, the $\mathrm{E} / \mathrm{I} \mathrm{MF}$ is useful not only as an index of airway narrowing but also as an index of mild eosinophilic airway inflammation. In addition, we have previously reported that the E/I MF is useful as an index of neutrophilic inflammation and mixedtype inflammation involving both eosinophils and neutrophils ${ }^{8}$ and it is useful as an index for the localization of airway narrowing and airway inflammation by examining lung sounds at seven sites in the thoracic wall. ${ }^{7}$

There are some limitations in this study, firstly the ICS treatments were introduced in various situations for the patients, and this might influence the levels of airway remodeling which consisted of the irreversible airway narrowing. Secondly, the subject number may be not enough. However, these limitations may not change the utility of the E/I MF, because these variabilities were also included in the multivariate analysis.

In conclusion, the $\mathrm{E} / \mathrm{I} \mathrm{MF}$, a parameter of LSA, can be used not only to detect remaining airway inflammation 
noninvasively in patients who have normal respiratory function but also as an index of airway narrowing in patients with asthma.

\section{Abbreviations}

LSA, lung sound analysis; FeNO, fractional exhaled nitric oxide; $\mathrm{FEV}_{1}$, forced expiratory volume in one second; FVC, forced vital capacity; $\mathrm{V}_{50}$ and $\mathrm{V}_{25}$, maximal expiratory flow at 50\% and 25\%; E/I LF, the expiration-to-inspiration sound power ratio in a low-frequency range; E/I MF, the expiration-to-inspiration sound power ratio in a midfrequency range; $\mathrm{PC}_{20}$, provocative concentration of acetylcholine causing a $20 \%$ decrease in $\mathrm{FEV}_{1}$; COPD, chronic obstructive pulmonary disease; ICS, inhaled corticosteroid.

\section{Acknowledgments}

The authors would like to thank Miss Oda and Miss Kojima for their technical assistance and for performing the statistical analyses.

\section{Author Contributions}

TS designed the study, participated in the data analysis and wrote the manuscript. YO assisted in the data analysis. YN assisted in the lung sound analysis. RK assisted in the examinations. SA assisted in the design of the study and revised the manuscript. All authors contributed to data analysis, drafting or revising the article, gave final approval of the version to be published, and agree to be accountable for all aspects of the work.

\section{Funding}

This study was supported by Fukuoka National Hospital research funding from 2011 to 2015.

\section{Disclosure}

The authors report no conflicts of interest in this work.

\section{References}

1. Barnes PJ. Therapeutic approaches to asthma-chronic obstructive pulmonary disease overlap syndromes. $J$ Allergy Clin Immunol. 2015;136:531-545.

2. Banaszak EF, Kory RC, Snider GL. Phonopneumography. Am Rev Respir Dis. 1973;107:449-455. doi:10.1164/arrd.1973.107.3.449

3. Forgacs P, Nathoo AR, Richardson HD. Breath sounds. Thorax. 1971;26:288-295. doi:10.1136/thx.26.3.288

4. Shreur HJW, Vanderschoot J, Zwinderman AH, Dijkman JH, Sterk PJ. The effect of methacholine-induced acute airway narrowing on lung sounds in normal and asthmatic subjects. Eur Respir J. 1995;8:257265. doi:10.1183/09031936.95.08020257
5. Shimoda T, Obase Y, Nagasaka Y, Nakano H, Kishikawa R, Iwanaga $\mathrm{T}$. Lung sound analysis and airway inflammation in bronchial asthma. $J$ Allergy Clin Immunol Pract. 2016;4:505-511. doi:10.1016/j. jaip.2016.02.001

6. Shimoda T, Obase Y, Nagasaka Y, Nakano H, Kishikawa R, Iwanaga $\mathrm{T}$. Lung sound analysis is useful for monitoring therapy in patients with bronchial asthma. $J$ Investig Allergol Clin Immunol. 2017;27:246-251. doi:10.18176/jiaci.0132

7. Shimoda T, Obase Y, Nagasaka Y, et al. Lung sound analysis helps localize airway inflammation in patients with bronchial asthma. $J$ Asthma Allergy. 2017;10:99-108. doi:10.2147/JAA.S125938

8. Shimoda T, Obase Y, Nagasaka Y, Asai S. Phenotype classification using the combination of lung sound analysis and fractional exhaled nitric oxide for evaluating asthma treatment. Allergol Int. 2018;67:253-258. doi:10.1016/j.alit.2017.09.004

9. Global Initiative for Asthma (GINA). Global strategy for asthma management and prevention. NHLBI/WHO Report. Bethesda National Institutes of Health, National Heart, Lung and Blood Institute. NIH Publication: 02e3659; 2017. Available from: www. ginasthma.org. Accessed October 01, 2019.

10. Metso T, Rytilä P, Peterson C, Haahtela T. Granulocyte markers in induced sputum in patients with respiratory disorders and healthy persons obtained by two sputum-processing methods. Resp Med. 2001;95:48-55. doi:10.1053/rmed.2000.0970

11. Silkoff PE. Recommendations for standardized procedures for the online and offline measurement of exhaled lower respiratory nitric oxide and nasal nitric oxide in adults and children. Am J Respir Crit Care Med. 1999;160:2104-2117. doi:10.1164/ajrccm.160.6.ats8-99

12. Tsurikisawa N, Oshikata C, Tsuburai T, et al. Bronchial hyperresponsiveness to histamine correlates with airway remodelling in adults with asthma. Respir Med. 2010;104:1271-1277. doi:10.1016/j. rmed.2010.03.026

13. Sato S, Saito J, Sato Y, et al. Clinical usefulness of fractional exhaled nitric oxide for diagnosing prolonged cough. Respir Med. 2008;102:1452-1459. doi:10.1016/j.rmed.2008.04.018

14. Shimoda T, Nagasaka Y, Obase $Y$, Kishikawa R, Iwanaga $T$. Prediction of airway inflammation in patients with asymptomatic asthma by using lung sound analysis. J Allergy Clin Immunol Pract. 2014;2:727-732. doi:10.1016/j.jaip.2014.06.017

15. Hamid Q, Springall DR, Riveros-Moreno V, et al. Induction of nitric oxide synthase in asthma. Lancet. 1993;342:1510-1513. doi:10.1016/ s0140-6736(05)80083-2

16. Payne DN, Adcock IM, Wilson NM, Oates T, Scallan M, Bush A. Relationship between exhaled nitric oxide and mucosal eosinophilic inflammation in children with difficult asthma, after treatment with oral prednisolone. Am J Respir Crit Care Med. 2001;164:1376-1381. doi:10.1164/ajrccm.164.8.2101145

17. Badiola C, Badiella L, Plaza V, Prieto L, Villa JR, Cimas E. Women, patients with severs asthma, and patients attended by primary care physicians, are at higher risk of suffering from poorly controlled asthma. Prim Care Respir J. 2009;18:294-299. doi:10.4104/ pcrj.2009.00027

18. Belloch A, Perpina M, Martinez-Moragon E, de Diego A, MartinezFrances M. Gender differences in health-related quality of life among patients with asthma. J Asthma. 2003;40:945-953. doi:10.1081/jas120024595

19. Zein JG, Udeh BL, Teague WG, et al. Impact of age and sex on outcomes and hospital cost of acute asthma in the United States, 2011-2012. PLoS One. 2016;11:e0157301. doi:10.1371/journal. pone. 0157301

20. Dursun AB, Kurt OK, Bayiz H, Ozkan E, Cakaloglu A, Karasoy D. Does gender affect asthma control in adult asthmatics? Chron Respir Dis. 2014;11:83-87. doi:10.1177/1479972314527468

21. Raherison C, Janson C, Jarvis D, et al. Evaluation of asthma severity in a cohort of young adults: is there any gender difference? PLoS One. 2009;4:e7146. doi:10.1371/journal.pone.0007146 
22. Nagasaka Y. Lung sounds in bronchial asthma. Allergol Int 2012;61:353-363. doi:10.2332/allergolint.12-RAI-0449

23. Anderson K, Aitken S, Carter R, Macleod JES, Moran F. Variation of breath sound and airway caliber induced by histamine challenge. Am Rev Respir Dis. 1990;141:1147-1150. doi:10.1164/ajrccm/141.5_Pt_1.1147
24. Habukawa H, Murakami K, Mochizuki M, et al. Changes in the highest frequency of breath sounds without wheezing during methacholine inhalation challenge in children. Respirology. 2010;5:485490. doi:10.1111/j.1440-1843.2010.01706.x

\section{Publish your work in this journal}

The Journal of Asthma and Allergy is an international, peer-reviewed open-access journal publishing original research, reports, editorials and commentaries on the following topics: Asthma; Pulmonary physiology; Asthma related clinical health; Clinical immunology and the immunological basis of disease; Pharmacological interventions and

Submit your manuscript here: https://www.dovepress.com/journal-of-asthma-and-allergy-journa new therapies. The manuscript management system is completely online and includes a very quick and fair peer-review system, which is all easy to use. Visit http://www.dovepress.com/testimonials.php to read real quotes from published authors. 